\title{
DE TRATAR, CURAR \\ Y SANAR POR EL CAMINO DEL HOLISMO
}

Edgard Alfonso Varela Guevara, $M D^{*}$

\section{Introducción}

Estar en un foro donde se consideren diferentes corrientes médicas, en este caso particular la medicina indígena y la no indígena, no debe ser entendido como un privilegio sino como una responsabilidad.

El ser humano siempre ha mostrado una preocupación por mitigar su dolor y en este afán ha intentado diferentes formas de cuidado (tratamiento), de aplicación de remedios y mantenimiento del estado de salud (curación) y diferentes maneras que aseguren la permanencia en el estado saludable (sanación). Así se origina la medicina y con ella los médicos. Podemos decir que la medicina es quizás tan antigua como el hombre mismo.

Queremos mostrar aquí, a nuestro amigo lector, contrario a lo que parece a primera vista, que existe tanta cercanía entre dos sistemas médicos: la medicina indígena y la medicina no indígena. Para recrear esta similitud reseñaremos sus objetivos, su origen, su desarrollo, sus alcances y los ofrecimientos que hoy en día hacen al individuo de nuestras sociedades de la post-modernidad.

No pretendemos hacer un extenso ensayo sobre el tema, sino tan solo mostrar un paralelo sobre algunos tópicos, nacidos de una despreocupada reflexión sobre estos sistemas médicos. Es nuestro objetivo generar la propia reflexión de nuestro amigo leyente, al igual que la hemos tenido nosotros.

Medico Internista, Cardiólogo, Epidemiólogo.Investigador Fundación Carare.

Conferencia dictada en el Hospital de San José, durante las jornadas sobre Medicina en el Arte prehispánico colombo-ecuatoriano, Septiembre de 2004.

\section{La mirada al hombre}

En la búsqueda del entendimiento del ser humano, la medicina no indígena propende por una visión integral del hombre aunque en la práctica ha disgregado al ser en lo corporal y mental. Y aunque algunas de sus disciplinas se ocupan del estudio de su emocionalidad y de las influencias de su microambiente familiar, laboral y social en el estado de salud, en general en el accionar diario el médico disgrega lo físico de lo emocional y tras su formación académica basada en la teoría de sistemas, tiende a un diagnóstico de enfermedad orgánica e instaura un tratamiento del órgano afectado. Pero al igual que en la medicina indígena realiza curaciones, formula medicamentos o da recomendaciones de cambios de sus hábitos de vida.

Quizás en la medicina indígena es más fuerte la concepción del hombre como una unión de su dimensión corporal, espiritual y social; y se entiende el pensamiento del paciente precisamente como ese puente entre lo corporal y lo espiritual y en una búsqueda integracionista del ser, desarrolla un sistema holístico para explicarse a sí mismo y un sistema holista de curación o la unión de múltiples conocimientos reunidos en torno de este objetivo. Y ahora más que antes, utiliza la medicina indígena recursos que pensaríamos le eran propios tan solo a la medicina no indígena.

\section{Objetivo de la medicina}

La medicina alopática busca el estado de salud y la define como el bienestar físico, emocional y social. Para ella el estado de enfermedad es la pérdida de este bienestar. 
En sus comienzos la medicina no indígena se preocupó de lo social y del medio ambiente (como lo sigue haciendo hoy en día la medicina indígena) pero con su desarrollo y el apoyo de la tecnología, se centra ahora en día en la búsqueda de los orígenes de la enfermedad, de agentes patógenos de transmisibilidad, de lo heredado, lo genético o de la predisposición dentro de los límites que ella misma se impone, para direccionar así las soluciones.

Esta medicina satisface la necesidad de bienestar para que el individuo pueda continuar persiguiendo los satisfactores de su multitud de necesidades. Pero debe reconocerse aquí que de intentar hacerlo se entendería como una extralimitación de funciones. Sin embargo, aunque no esta institucionalizado en esa comunicación médico paciente, ese límite desaparece y el médico no indígena acompaña al paciente y su familia.

El recorrido hacia el cumplimiento de estos objetivos de curación en la medicina no indígena se enturbian con los modelos económicos imperantes en nuestras sociedades, pero en su más pura concepción y en la práctica diaria en tanto que pueda despojarse de esas presiones, tiene el médico no indígena al igual que el indígena los más nobles sentimientos y los pone al servicio de su paciente.

En la medicina indígena la salud no parte de lo físico sino de lo espiritual, la curación reestablece el desequilibrio interno de cada ser. El entorno se entiende no solo como la relación del ser con el medio ambiente como materia, pues esa materia es en sí misma espíritu. Para esta medicina la salud está definida como la armonía del ser consigo mismo, con su entorno y con Dios ${ }^{1}$. Esta curación que armoniza tiende a la búsqueda de soluciones de la problemática cotidiana y a una verdadera proyección del individuo que incluye su espiritualidad. El uso de la armonía alcanzada trasciende las necesidades materiales; por tanto la matriz de necesidades y satisfactores no opera como lo hace en la mirada no indígena. Los hijos de la medicina indígena tienden a aumentar necesariamente su espiritualidad.

\section{De los orígenes de la medicina y su conocimiento}

La medicina alopática nace de la preocupación por explicarse lo interno y por explorarlo para poder controlarlo. Partiendo de métodos de ensayo y error y de la observación, pasa por la pseudo-experimentación e intenta hoy en día regirse por el método científico, la reproducibilidad y lo basado en la evidencia.

No reconoce explícitamente un origen divino del conocimiento y todo se debe a las capacidades del hombre científico y creativo del médico observador y crítico. Tiende a buscar el conocimiento mediado por el lucro.

La medicina indígena reconoce una transmisión del conocimiento por tradición, una sabiduría que viene del espíritu mismo de la naturaleza y que ha sido puesta allí por la Divinidad. Pero de igual forma, aunque el reconocimiento de lo Divino no se hace tan explícito en la medicina no indígena, tampoco podemos decir que se niegue.

La medicina indígena usa el inconsciente colectivo, la sabiduría universal o aún va al más remoto lugar donde esté el conocimiento cuando sea necesario. Incluso, lo obtiene en forma directa de Dios. Para esta medicina toda la sapiencia es entregada al curandero por Dios mismo para el hombre.

\section{El acto médico}

En la medicina no indígena unos médicos trabajan lo corporal y entregan a psicólogos o psiquiatras el manejo de lo emocional. En su concepción sistémica favorece la aparición de supraespecialistas (que llaman subespecialistas) que puedan ocuparse de cada órgano o aún de cada tejido del órgano. Posee algunos grupos integralistas y de médicos de familia que se contraponen a la mirada separatista.

Desde el punto de vista macro en los modelos anteriores del estado paternalista, podía encontrarse 
con frecuencia un acto médico bondadoso o al menos con afán de conocimiento. Pero en la actualidad el médico es obligado en ocasiones y en otras es partícipe de un acto médico enturbiado por la ley de oferta y demanda, la economía de escala y el liberalismo salvaje. Del acto médico en la medicina no indígena siempre alguien se lucra.

No se considera en general el estado físico ni emocional de quien practica la medicina. Y menos aún se tiene alguna consideración sobre su espiritualidad. De hecho, casi separa el comportamiento personal, sus valores y la moral en su vida propia, de la vida profesional. Sin desconocer aquí los mecanismos de vigilancia que la regulan.

En ocasiones usa un acto médico arrogante, con incertidumbre que explica por la teoría estocástica, usa medicamentos con la intención de tratar, medicamentos que poseen un espectro amplio de resultados desde la curación hasta eventos adversos leves o aún letales. Pareciera que cada vez más el acto médico no cubriera las expectativas de sus pacientes.

En la medicina indígena el acto médico tiende al holismo y las fronteras del holismo son en el ilimitadas. Cada acto médico es en sí una plegaria a Dios, pues busca a través de lo Divino el tratamiento, realiza con él la curación y si Dios lo permite, sana. El curandero, el médico indígena o el chamán son mediadores entre diferentes mundos y el mundo Divino. Pero también cada acto médico es un acto de contrición que ocurre gracias a la bondad y humildad del curandero. Por eso no es extraño que cada acto médico no sea otra cosa más que un encuentro personal con Dios.

El médico indígena se especializa en la cura de todo mal. Y se ocupa de enfermedades como la pereza, el odio, la rabia o la ambición, por ejemplo. Tener o no la capacidad para curar se basa en mantener la propia curación de cuerpo y espíritu del médico, es una capacidad ganada y que puede mantenerse, incrementarse o perderse de acuerdo con sus actos.
El acto médico en la medicina indígena busca curar mediante un proceso certero y perfecto que plantea soluciones. En los remedios que usa no hay cabida a los efectos colaterales o adversos.

\section{Realidad}

Hemos presentado una visión de cada sistema y damos gracias a Dios por las bondades que cada uno de ellos ha entregado a la humanidad. Por el vertiginoso desarrollo científico, por el andamiaje tecnológico de apoyo a la labor del médico, por el dimensionamiento del ser con desarrollo de su espiritualidad, por la permanencia de un Dios cotidiano, logrados con estas dos corrientes de la medicina.

Entendemos el aumento al interior de las ciudades de la utilización de la medicina indígena y la proliferación de las prácticas de medicina alternativa por el deterioro de un sistema médico imperante que alejado de Dios, se encuentra alejado del ser necesitado y la implementación de un sistema que se lucra de la enfermedad del hombre, pero que no le entrega soluciones.

Nuestro reconocimiento a todos aquellos médicos que con su accionar cualquiera que sea su disciplina han enaltecido al ser. Mostrar como la medicina no indígena y la indígena cubren objetivos similares, con algunas diferencias de forma, pues en esencia son iguales, es un aliciente para que enfrentando las adversidades, cada médico indígena o no indígena sea capaz de explorar a través del rostro de su paciente su enfermedad, su dolor, su sufrimiento, pero también sus sentimientos, preocupaciones, cargas, penas, anhelos, felicidad y sus proyecciones; en una palabra su realidad pasada y presente para ayudar a construir su realidad futura.

\section{Referencias}

1 Gaitán O, Tamara L, Trujillo J, Aldana D. Conceptos de salud y enfermedades alrededor de las ETS, el VIH y el SIDA, en las comunidades indígenas Inga, Siona, Kamentsá del departamento del Putumayo y Zenú de los departamentos de Córdoba y Sucre. Bogotá, Ministerio de Salud, 2000. 